\title{
Using Educator Characteristics on Attitudes toward Inclusion to Drive Professional Development
}

\author{
Jess L. Gregory*, Tisha A. McCoy, Michelle F. Baker and Amy L. Fedigan \\ Department of Educational Leadership and Policy Studies, Southern Connecticut State University, New Haven, \\ United States \\ Email: gregoryj2@southernct.edu
}

\begin{abstract}
Students with mild to moderate disabilities are included in classes whether or not the teacher holds the necessary attitudes to help that student achieve success. This research seeks to present four perspectives on how leaders at different levels can use the same information regarding educator attitudes towards inclusion to promote student learning and encourage professional development in the settings in which they lead. Districts, schools, and individual leaders can change pedagogical practice through assessing educator attitudes, providing differentiated professional development, and establishing policies that support inclusive education.
\end{abstract}

Keywords: Inclusion, educational leadership, professional development, attitudes.

\section{Introduction}

It is essential that leaders at all levels know how to meet the needs of the educators they lead to best meet the needs of all the students in their care regardless of a student's exceptionality. Students with mild to moderate disabilities are included in classes whether or not the teacher holds the necessary attitudes to help that student achieve success. The teacher's attitude is the greatest determinant as to whether the student will be successful in school (Ahmmed, Sharma, \& Deppeler, 2012; Avramidis, Bayliss, \& Burden, 2000; Avramidis \& Norwich, 2002). This research seeks to present four perspectives on how leaders at different levels can use the same information regarding educator attitudes towards inclusion to promote student learning and encourage professional development in the settings in which they lead.

Maximizing student outcomes is connected with not only positive teacher attitudes toward inclusion but also to increased levels of teacher stress (Barnes \& Gaines, 2015). In the United States, a child's right to a free and appropriate education was established through legislation in 1975, but the recent increase in the inclusion of students with mild to moderate disabilities has accelerated since the implementation of the No Child Left Behind Act (Education for All Handicapped Children Act, 1975, No Child Left Behind Act. Reauthorization of the Elementary and Secondary Education Act, 2001). With the increase of accountability, teachers face pressures to have all students achieve at the highest level, as measured by a high-stakes test. Barnes and Gaines (2015) report that the stress teachers feel negatively impacts their attitude towards inclusion, and diminishes the educational outcomes for all students.

The support a leader provides can reduce teacher stress and encourage faithful implementation of inclusion (Ainscow, Dyson, \& Weiner, 2014). Not all educators share the value of inclusion, in fact, nearly half of teachers do not support inclusion as a best practice (deBettencourt, 1999; Glazzard, 2011). If a school leader seeks to develop inclusion to be more than just having children share the same classroom space (Avramidis, Bayliss, \& Burden, 2000a, 2000b; Dudley-Marling \& Burns, 2013) then he or she must shift the attitudes of these teachers (Ainscow et al., 2014; Noto \& Gregory, 2011).

Classroom teachers are a learner's best chance for academic success. Teachers have the primary responsibility for differentiating instruction according to students' specific needs and providing intervention when needed (Ford, 2013; Reeves, 2011; Tomlinson, 1999). Response to Intervention (RTI) is a three tiered model for delivering instruction. In Tier 1, teachers deliver the core curriculum that all students can access. Students who need more support in addition to the core curriculum would fall in 
Tier 2. Teachers deliver small group instruction in areas of academic difficulty. In Tier 3, students receive more intensive interventions (Stuart \& Rinaldi, 2009).

Within the RTI model, all tiers require high quality teaching and differentiation. This includes the inclusion of students with exceptionalities. A review of literature shows that all school levels elementary, middle and high school have common key components (Fuchs, 2010; Pritchard, 2014). There needs to be high quality effective general education instruction, data driven decision making, tiered interventions, progress monitoring, and a team approach to instructional decision making. Benefits for implementing RTI spans across all school levels. RTI reinforces a common language about teaching, learning, and behavior systemically.

Evidence based instruction is implemented in each school level (elementary, middle, and high) across the district (Avramidis \& Norwich, 2002; Wilde \& Avramidis, 2011). Data team based decision making promotes thinking and collaborating for all learners (Bryk \& Schneider, 2002). The emphasis is on high quality teaching and differentiation in all tiers. Collaboration in planning and implementation of the curriculum provides support for all tiers of learners (Bryk \& Schneider, 2002). Educational leaders drive the instructional environment for teachers and students in their building (Elmore, 2000; Furman \& Shields, 2005).

\section{$1.1 \quad$ Purpose}

The purpose of this study is to explore how school level and teacher level characteristics impact teacher attitudes toward the inclusion of students with mild to moderate disabilities and how educational leaders at different levels can use this information to promote successful inclusive practices. Through a better understanding of the factors that may influence teacher attitudes, leaders can create policies and implement practices that support inclusive efforts so that all students have the opportunity to access the curriculum and maximize their potential.

\section{Background}

Data drive decision making for leaders, and tracking the characteristics of a faculty is relatively straightforward. Because of this, it would be useful to identify which characteristics can be linked to educator attitudes towards inclusion, as these may impact the decisions made regarding the expenditure of limited professional development resources. The restrictions on how much money and personnel time are available to devote to professional learning enhance the need to optimize every professional development opportunity. Dingle, Brownell, Leko, Boardman, and Haager (2011) found that individual educator qualities influenced the learning extracted from professional development and how well the educator implemented the material presented in the professional development. Therefore, knowing the characteristics of a faculty can help the district or school leader plan professional development experiences that are most likely to have an impact on learning.

A characteristic of a faculty that impacts educator attitudes is the grade level taught by the faculty. Educators of younger grades held more positive attitudes toward inclusion than those of older grades (O'Rourke, Main, \& Cooper 2008). This level of positivity and openness is consistent with other research that connects the decline in positivity to the increase in specialization and content area expectations (Shippen, et al. 2011). Elementary educators may move between grades at the elementary level, but are generally responsible for all the content areas. At the secondary level, the educators are content area specialists and have less flexibility to teach across the whole school. While he or she may know the child in terms of the discipline he or she teaches, it is less likely that they will feel responsible for the child in other contexts, nor might the content specialist feel confident meeting needs beyond his or her discipline.

Another characteristic that the leader can manipulate is the experience that faculty have had interacting with children with different learning needs. Ahmmed, Sharma, and Deppeler (2012) determined that contact with a student with a disability was a significant predictor of teacher's attitude. Avramidis, Bayliss, and Burden (2000) determined that teachers who had more experience with inclusion had more favorable attitudes than those educators who had little or no experience with inclusion. This finding is contradicted by Gal, Schreur and Engel-Yeger (2010), who found that there was no significant correlation between teacher attitude and the teacher's past experience with children 
with disabilities. Also the work of Ball and Green (2014) showed that educational leaders with more experience had more negative attitudes toward inclusion. Experience is a factor that the leader can influence. Through policies and scheduling, the leader can set faculty up to have more social and academic interactions with children with mild to moderate disabilities which, over time, build a faculty's confidence in meeting the needs of all children.

When considering years of experience, the published research presents a less coherent message. There was some conflation of age and experience in the research. Additionally, there are conflicting studies on how these characteristics connect to educator attitudes towards inclusion (Avramidis, Bayliss, \& Burden 2000; Parasuram 2006). For example, Beacham and Rouse (2012) reported that while changing educator attitudes towards inclusion was difficult, younger educators were more flexible in their views. Gal, Schreur and Engel-Yeger (2010) noted that teacher's age was correlated with attitude towards children with disabilities, finding that older teachers had significantly less positive attitudes.

\section{Theoretical Lenses}

\subsection{Brunswik's Lens Model}

This study is guided by Brunswik's Lens model (1955) and grounded in the theory of planned behavior (Ajzen, 1991; Netemeyer, Ryn, \& Ajzen, 1991). As a result of every individual in a school impacting the other individuals in a school, it is crucial to this research to integrate how a seemingly similar setting may be experienced differently by the individuals in that setting. Brunswik's lens model, and with a larger view, probabilistic functionalism help to shape this undertaking. Every individual is continually bombarded with sensory information, but the brain filters that information and while most of the information is rejected, some information is retained in short-term memory, and then a small portion of that information is retained in long-term memory. This filtering is based on whether the information is deemed useful. Each evaluation that is made is based on the limited amount of information that was retained from prior experiences. So all future decisions about the value of a stimulus are based on the decisions that have already been made about what information is worthy of retention. This represents the probabilistic functioning of decision making.

Refining the application of probabilistic functionalism to Brunswik's Lens model, Brunswik posits that past experiences (distal stimuli) are focused through a lens of current events (proximal stimuli) and then are used to evaluate options and make a judgment. Additionally, the past experiences influence the credibility of the stimuli, the reasonableness of strategies and the value of possible responses. Every individual makes subconscious judgments of what information is worthy of note and what is noise, these judgments are based on prior experiences, so that having four researchers with different backgrounds approach the same data set provides a deeper look into the proximal stimuli (the data) based on the differing backgrounds (distal stimuli) of the researchers. For this current study, the four researchers embody multiple lenses of educational leadership (assistant principal, principal, assistant superintendent, professor, and public school board member). Each researcher brings with her a different lens through which to analyze the same data set, and the integration of these views provides a richer treatment of the data than each individual researcher could on her own.

\subsection{Theory of Planned Behavior}

Leaders, in order to effect change in their schools, must utilize what they know about influencing the behaviors of the teachers in their buildings. The theory of planned behavior provides a mechanism to do just this. The theory of planned behavior links how a teacher's attitudes, the subjective norms in the building and his or her perceived control contribute to a behavioral intention and ultimately to the teacher's behavior (Figure 1) 


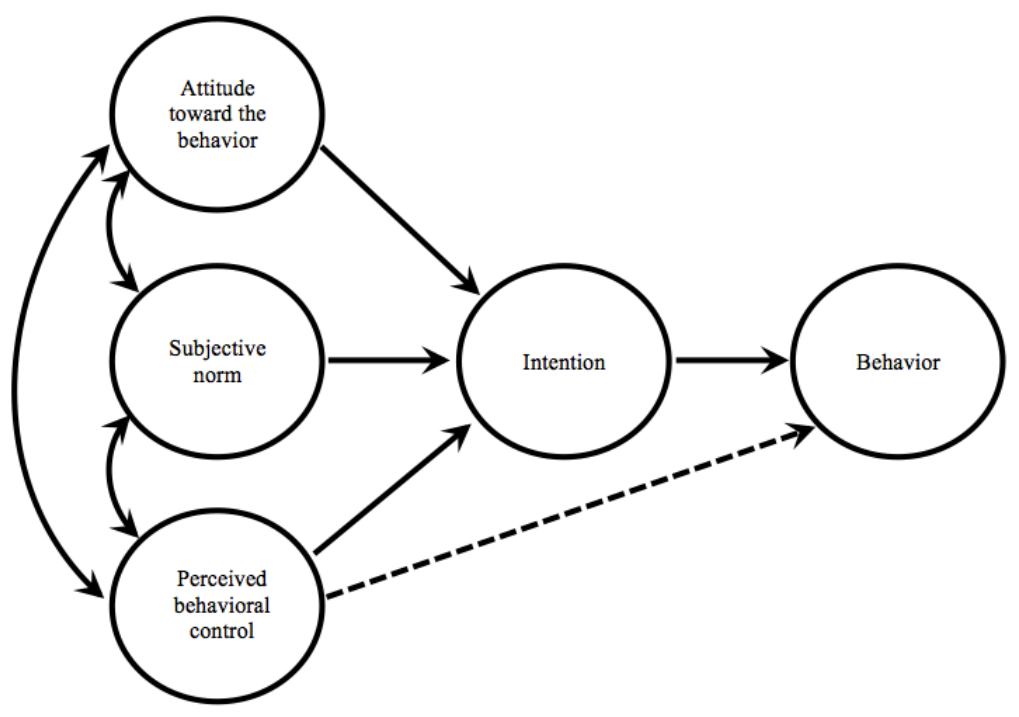

Figure 1. Diagram of the theory of planned behavior (adapted from Ajzen, 1991).

While the theory of planned behavior includes three variables feeding into the behavioral intention, only one of these three is also posited to influence the behavioral action as well as perceived behavioral control. This variable may be operationalized as self-efficacy, not competence or skill. Perceived behavioral control focuses solely on the individual's perception of whether they have control in a situation, independent of the actual level of control. Gregory, Lewis, Noto, \& Margolis (2011) found that educators in urban environments felt that the ability to effect change was just one level beyond them, regardless of the educator's level. That is, the teacher felt that the power was held by the building leadership, and the building leadership reported that the power rested with district leadership. This perceived lack of control absolves the educator of responsibility, akin to Whitaker's adaptation of Passing the Buck Down the Line (Whitaker, 2003). While this element of the theory of planned behavior is beyond the current study, it can be operationalized as shared governance/leadership. This will be included in the discussion of the data as fostering a sense of self-efficacy at all levels is the educational leader's responsibility.

A school leader shapes the climate of a school (Gregory, n.d.; Gregory \& Fitzpatrick-Hanna, n.d.; Leithwood \& Riehl, 2003; Peterson \& Deal, 1998) and that climate is indicative of the subjective norms of the group (Bock, Zmud, Kim, \& Lee, 2005). While Ajzen includes both attitude and subjective norms as equivalent predictors in his model, subsequent work has shown attitude to be a stronger predictor of behavioral intention (Sheeran, Norman, \& Orbell, 1999). Therefore, the current study focuses on the attitudinal dimension of this model.

\section{Method}

The focus of this quantitative research is to investigate how school level and teacher level characteristics influence teacher attitudes toward the inclusion of students with mild to moderate disabilities. And secondly, how can leaders at different levels use this information to promote successful inclusive practices. These research questions were evaluated through the self-reported, the Attitudes Toward Teaching All Students instrument (ATTAS-mm).

\subsection{Participants}

Researchers at 8 sites across the United States surveyed 903 participants with the ATTAS-mm and the accompanying demographic questionnaire. Data were collected in Bridgeport, CT, Bryan, TX, Fayetteville, GA, Harlem, IL, Houston, TX, Peachtree City, GA, Philadelphia, PA, and Newark, NJ. 


\subsection{Instrumentation}

The Attitudes Toward Teaching All Students instrument (ATTAS-mm) was presented publicly in 2012 (Gregory \& Noto, 2012). The instrument evolved from an earlier instrument that focused solely on preservice teachers (APTAIS; Cullen \& Noto, 2007) and an instrument that demonstrated reverse score bias (TATIS; Cullen et al., 2010). The reliability for the full ATTAS-mm scale is good $(\boldsymbol{\alpha}=0.833)$ according to generally accepted values and the three subscales boast good to excellent reliability $(\boldsymbol{\alpha}=$ $0.720, \boldsymbol{\alpha}=0.928, \boldsymbol{\alpha}=0.837)$. Subscale scores range from 3 to 21 and the full scale scores span from 9 to a maximum of 63 . The ATTAS-mm demonstrates both face and construct validity as it has been peer reviewed and designed with the triadic model of attitudes proposed by Fishbein and Ajzen (1972) that laid the foundation for the theory of planned behavior (Ajzen, 1991) to be used in this study.

The ATTAS-mm instrument consists of a set of demographic questions and then a set of nine Likertscale items that utilize a 7 -point scale. The wider scale permits more gradation in responses as there are some elements of attitudes towards inclusion that may be subject to skewing due to socially desirable responses. There is no linking of individuals to their scores to reduce the likelihood of respondents providing socially desirable responses, and the researchers are not connected to the research sites in any way so as not to influence the respondents or their future employment. Even so, some respondents did not respond to some of the demographic items.

\section{$5 \quad$ Results}

According to these data, at the school level there are significant differences in overall educator attitudes towards inclusion based on school type $\left(\mathrm{F}_{\text {full }(3,717)}=7.14, \mathrm{p}<.001 \eta^{2}=0.029\right)$ and significant differences based on community type $\left(\mathrm{F}_{\text {full }(4,432)}=82.77, \mathrm{p}<.001 \mathrm{n}^{2}=0.436\right)$. At the educator level there were statistically significant differences according to sex $\left(\mathrm{t}_{(344.67)}=-2.35, \mathrm{p}=.019, \mathrm{~d}_{(\text {Cohen })}=0.192\right)$, years' experience $\left(\mathrm{F}_{\text {full }(4,830)}=21.84, \mathrm{p}<.001 \mathrm{\eta}^{2}=0.095\right)$, highest degree earned $\left(\mathrm{F}_{\text {full }(5,756)}=72.24, \mathrm{p}<.001 \mathrm{\eta}^{2}\right.$ $=0.323)$, number of courses taken in special education $\left(\mathrm{F}_{\text {full }(3,691)}=5.01, \mathrm{p}=.002 \eta^{2}=0.021\right)$, and the amount of experience that educators had with student that have mild to moderate disabilities $\left(\mathrm{F}_{\text {full }}(3,726)\right.$ $\left.=5.04, \mathrm{p}=.002 \mathrm{\eta}^{2}=0.021\right)$. Further analyses were conducted on the subscales and offer interesting insights.

\section{Discussion}

\subsection{School and District Characteristics}

While the leader cannot change the characteristics of the school he or she leads, if there are differences in one or more domains of educator attitudes associated with different characteristics, then this would be "low hanging fruit" in terms of applying the theory of planned behavior without requiring the leader to differentiate for individual educator characteristics.

\subsubsection{School Type}

For the purposes of this research, respondents were asked to identify whether they were teaching in an elementary, middle or secondary school setting. Noting that there are an abundance of different configurations of school settings, the demographic questions offered some advice on how to classify the school. An elementary school setting was defined as k-2, k-3, k-4, k-5, or k-6. Just over forty-four percent of the sample $(44.4 \%)$ that responded to the question indicated that they taught in an elementary type setting. The question described a middle school as one with grades 4-6, 5-6, 4-8, 6-8, or 7-8 and just over ten percent of the sample (10.1\%) selected that option. Finally, secondary or high schools were defined as 7-12, 8-12, or 9-12. Secondary school educators comprised $43.8 \%$ of the sample. Twelve respondents $(1.7 \%)$ indicated an alternate choice selecting the "other" option. There were 182 responses that did not indicate a school type, this is about twenty percent of the sample overall, leaving the analyses to be conducted on the remaining sample $(\mathrm{n}=721)$.

According to these data, there are significant differences in overall educator attitudes towards inclusion based on school type $\mathrm{F}_{(3,717)}=7.14, \mathrm{p}<.001 \mathrm{\eta}^{2}=0.029$. While there were no significant 
differences in the full scale between the responses of elementary and secondary educators, the middle school educators reported much higher scores $(\mathrm{p}<.001)$ on the ATTASmm. The results from this sample run counter to that of Shippen et al. (2011) and O'Rourke, Main and Cooper (2008), who found that elementary educators had more positive attitudes towards inclusion. One middle school Principal remarked that she promoted inclusion in her school through teaming teachers across disciplines, and providing opportunities for the middle school educators to visit the local elementary schools (personal communication, 8-10-15). The visits focused on how the elementary educators were differentiating for children. The willingness to bridge practices from elementary classrooms to the more discipline specific middle school curricula appears to be an indication of the flexibility of middle school educators.

\subsubsection{Community Types: Rural, Suburban, and Urban}

When considering school characteristics that may impact educator attitudes towards inclusion, the type of community is near the top of the list. Levels of funding, parental involvement, community support, and political agendas all affect schools. With the broadest brush strokes, communities can be divided into three categories: rural, suburban, and urban. This is not to say that every rural community is homogeneous, and likewise suburban and urban, but rural communities tend to have different issues than suburban and urban do.

There were a number of educators who did not identify the type of community in which they lived $(n=73)$. This group was included separately in case there was something interesting about educators that either cannot or choose not to describe the community in which they work. None of these 73 educators provided gender or highest degree information. Of the information the educators did provide, the distributions of school type, years of experience, number of courses in special education taken, and experience with children with mild to moderate disabilities were all similar to the rest of the sample. Further investigation does not merit excluding the 73 educators from the analyses.

The full scale and all three subscales demonstrate statistically significant differences based on community type $\left(\mathrm{F}_{\text {full }(4,432)}=82.77, \mathrm{p}<.001 \mathrm{n}^{2}=0.436\right)$ The effect size of 0.436 is substantial, but recall that not everyone in the sample chose to share demographic information. Caution is warranted in this interpretation based on the anomalies present in the group that did not identify the community type.

The scores of educators who indicated they worked in urban areas demonstrated the highest cognitive subscale results $(\mathrm{p}=.004)$. This is a boon for a leader in an urban setting. Unlike the rural and suburban setting, the urban leader will not have to devote precious time to establishing a common foundation of knowledge. For the leader that is in a rural or suburban setting, using an open type of assessment like a multiple choice electronic response or clicker presentation will have the faculty engage with content about inclusion without any judgment (Gregory, 2013). Notice that there is assessment here without judgment. The clicker allows the faculty as a whole to respond, and then the leader can facilitate a discussion around popular responses and if different, the correct response. If there is a demonstrated need for more content instruction, the leader can determine whether this is something that can be handled through self-study, learning communities, webinars with follow up discussion groups or more formal educational opportunities. Urban leaders, if they can allocate the resources, may find this type of assessment without judgment useful for getting to know where their particular faculty are in terms of knowledge about inclusion.

While the cognitive subscale results were high for the urban educators, the affective were significantly lower than the results of suburban educators $(\mathrm{p}=.025)$ and lower than the rural educators $(\mathrm{p}=.067)$. Based on this information, the urban educators in this sample know what needs to be done, but are not as emotionally connected to the ideas of inclusion nor do they feel a professional responsibility to act on them, the behavioral domain was also lower than the cognitive. The dissonance between the cognitive and the other two domains may be rooted in the very standards of the profession. The InTASC standards highlight that teachers and special educators work jointly to design and deliver instruction and that the teacher accesses specialized assistance to meet different learning needs (CCSSO 2011). This can be interpreted that the general educator is not prepared to meet the needs of students with special needs on his or her own, nor is it his or her responsibility. Internalized by educators, this may account for lower affective and behavioral subscale results.

A challenge for leaders attempting to impact the affective domain is that this domain is closely connected to the educator's core values. It emphasizes the emotional connections and level of acceptance that the educator has rather than the amount of information that he or she can recall. To change the 
affective domain is a deep level of change, described by Watzlawick, Weakland and Fisch (1974) as second-order change, change that requires a systematic change not merely a superficial one. Nuhfer (2005) recommends practices that would now be labeled as mindful practices such as noting and then reflecting on teachable moments for oneself regarding teaching, or creating an environment that permits being fully present like listening to soothing music before class, and using techniques to be more present. He recommends practices that focus on becoming more self-aware; to connect with personal feelings and thereby become more connected to the affective domain. In a group setting, this personal growth requires a high level of trust.

To be honest and open about the affective domain also makes one vulnerable. If there is a high trust culture, then an activity like De Bono's (1985) Six Thinking Hats, can be used to make hidden processes more open and promote difficult discussions that will facilitate the desired, second order, affective change. While this technique can be used to promote collaboration by assigning different roles, hats, to individuals and the individual wears that hat through the whole exercise, or focus a group by having everyone wear the same hat at the same time to analyze an issue, it can also be used in a round to highlight the affective domain, by rotating the hats. To do this, each educator will wear each color hat at some point during the exercise and journal their experience with that hat.

Connecting back to the theory of planned behavior, a group exercise like the Six Thinking Hats used in a round can not only influence the affective domain of attitude, but also the subjective norms. Additionally, any misconceptions about barriers to implementation might surface and these can be dispelled further enhancing the likelihood of changes in educator behaviors. It is important to stress that a group activity requires a positive, trusting environment to be effective. A leader must assess the culture and climate of the school before attempting this type of activity and if the culture and climate are not yet acceptable, then it is crucial to invest in developing a more positive, open, healthy environment as this will benefit both the adults and the children in the school.

\subsubsection{Summary}

The school characteristics, both school type and community type provide some insights into educator attitudes towards inclusion and support university preparation and in-service professional development that targets the behavioral domain for secondary educators and the affective domain for urban educators. In general, to influence educator attitudes, designing activities and experiences that respect and utilize the cognitive background that suburban and urban educators already possess will make them more receptive to the possible influencers on the affective and behavioral domains. In rural schools, it appears that providing some background information on how and why inclusion benefits all students and how educators can effectively implement inclusion will bolster efforts to increase the affective and behavioral domains of attitude to ultimately drive behaviors.

\subsection{Educator Characteristics}

Unlike school characteristics, educator level characteristics will vary within a faculty. Leaders are charged with assessing which educators will benefit most from what types of professional development, even when the educators themselves may not be aware of their needs. An additional confounding factor is that some educator contracts constrict what a leader can do to assess the needs of faculty, and while a leader may wish to differentiate professional development experiences based on educator characteristics, it is not always appropriate to do so. It would be a mistake to discriminate between groups based on gender. Years of experience may be conflated with educator age, so if there are targeted professional activities for groups with different numbers of years' experience, a leader will have to be very explicit that it is experience, and not age, that is being used to determine groups.

\subsubsection{Gender}

Leaders will be able to do very little to differentiate professional learning experiences based on gender without drawing fire for gender discrimination - since, by definition, they would be discriminating the groups based on gender. There was a significant difference in results based on gender for the full scale, $\mathrm{t}_{(344.67)}=-2.35, \mathrm{p}=.019, \mathrm{~d}_{(\text {Cohen })}=0.192$, with women reporting higher scores than men, with a low effect size.

The current data generally affirm the mixed findings of prior research. For the theory of planned behavior, the behavioral intention, that part of attitude, is crucial. It is of interest that the affective and 
behavioral subscales are more closely matched than either is to the cognitive. This could be evidence of what Gal, Schreur, and Engel-Yeger (2010) discuss regarding instrumentation that cues to a "right" response. An educator may choose a "right" response based on what they know about inclusion (cognitive) but do not pick up on what the "right" answer should be on the other two subscales, or the affective and behavioral domains on the instrument do not offer clear "right" answers. Both genders parallel the higher cognitive and lower affective and behavioral scores.

\subsubsection{Years' Experience}

New educators, those with up to four years' experience, reported significantly more positive attitudes than those with five to nine years' experience, but significantly lower than every other group $\left(\mathrm{F}_{\text {full }}(4,830)\right.$ $\left.=21.84, \mathrm{p}<.001 \mathrm{\eta}^{2}=0.095\right)$. According to Boivie, "once teachers have about five years' experience, they are most productive" (2011, 3). Marrying this with the data above, the novice teachers, those with 0-4 years of experience have not yet peaked according to Boivie, but they have more positive attitudes than the teachers that have peaked, those with 5-9 years' experience. Other research finds that while there is the most teacher growth in the first few years, improvement continues throughout an educator's career (TNTP, 2012). With the exception of the significant dip in the 5-9 year group $(\mathrm{p}=.011)$ the upward trend in attitudes is congruent with these findings.

Leaders can use these data to leverage policy decisions and programming designed to retain experienced faculty. Programs that compensate experienced faculty to mentor newer faculty members will also foster communication and spread the more positive attitudes that more experienced faculty members have. Leaders are encouraged by these data to do everything they can to keep faculty who have ten years' experience or more and to look for ways to assist faculty in years 5-9 to get over this challenging time in their career. It might be worthwhile to evaluate whether educators in years 5-9 have more child care and elder care stressors that make them less positive. If this is the case, then leaders would be well served to look for innovative options to minimize additional stressors such as offering flexible schedule options. A flexible schedule will be a more natural fit in middle and secondary grades, but could be possible in elementary grades with a co-teaching model or less conventional scheduling.

\subsubsection{Highest Degree Earned}

School leaders have little influence when it comes to the gender composition of their faculty and only minimally more regarding the number of years' experience faculty have. For example, a school leader cannot specify that he or she only wants senior educators in his or her school, but the leader can encourage experienced educators not to retire when they are eligible; the leader doesn't hold the power to mandate or prohibit an educator to retire, but can strive to influence the decision. Leaders do have greater means to influence the highest degree a faculty member earns through policies that encourage or inhibit faculty pursuing additional degrees once he or she is a faculty member. The data suggest that generally, educators with higher degrees hold more positive attitudes towards inclusion. Educators who have earned a Master's degree and an additional 30 credits have higher reported scores on all three domains and the full scale than those that have fewer academic credentials $\left(\mathrm{F}_{\text {full }(5,756)}=72.24, \mathrm{p}<.001\right.$ $\left.\eta^{2}=0.323\right)$. Even with the very small $n$, the scores of the respondents with a doctorate were statistically significantly higher than every group except the respondents who have a Master's degree and an additional 30 credits.

When evaluating the full scale, the level of educator has a significant, positive effect on educator attitude toward inclusion $\left(n^{2}=0.323\right)$, and with the exception of the small number of respondents that hold a doctorate, every group was significantly different from each other. Educators with an AS reported the lowest scores $(\mathrm{p}=.023)$, higher were those reported from BA level educators $(\mathrm{p}=.023)$, then those holding the MA $(\mathrm{p}<.001)$, and finally the MA+30 $(\mathrm{p}<.001)$. The few doctoral level educators reported full scale scores that fell between the MA and the MA+30, but were statistically comparable.

To capitalize on this information, leaders can encourage faculty to pursue higher degrees by developing policies such as tuition reimbursement or partnering with local universities to offer classes in the district. This removes the logistical impediments that deter some faculty from starting on the path to a higher degree. There are also non-policy ways that a leader can influence faculty to attain a degree. Leaders can offer information on and support for finding and applying for grants and scholarships to make pursuing an advanced degree more manageable. Other non-policy methods include asking faculty who are currently in courses towards an advanced degree how their classes are going and if there is something from their courses that they might be willing to share with the larger faculty. A leader can 
also steward a professional library that includes texts that are relevant to coursework that faculty might be taking. These gestures go a long way to influence the culture to become one that values continuous learning and earning of advanced degrees.

\subsubsection{Number of Courses Taken in Special Education}

Similarly, leaders have the power to influence faculty to take individual courses that are specifically focused on special education. The data in this study indicate that there is a diminishing return on this sort of coursework. Full scale scores peak in the educators with 1-3 courses in special education, with the scores demonstrating statistically significant differences $\left(\mathrm{F}_{\text {full }(3,691)}=5.01, \mathrm{p}=.002 \eta^{2}=0.021\right)$. Educators with 1-3 courses reported results that were significantly higher on the full scale than those reported by educators with no courses in special education $(\mathrm{p}<.001)$, and slightly higher than the scores reported by educators that had taken 4 or more courses $(\mathrm{p}=.280)$. When the results are disaggregated by attitudinal components, unsurprisingly, educators with more courses in special education $(4+)$ reported higher scores on the cognitive domain, but these were not significantly different from the scores of educators with 1-3 courses $(\mathrm{p}=.060)$. In the affective domain, there were no significant differences between the groups of educators that had taken no courses in special education and those that had taken $1-3(\mathrm{p}=.110)$ or $4+(\mathrm{p}=.661)$ as they fell between the two other groups. However, there was a significant difference between the group that has taken 1-3 classes and those that have taken more classes $(\mathrm{p}=.044)$.

Ultimately, these results suggest that more coursework after a point is associated with less desirable attitudes towards inclusion. A leader may want to encourage faculty to pursue venues other than formal coursework in special education to interested faculty members, so long as they have already completed at least one course in special education. Most states require at least one special education course before becoming certified. (At least one state, GA, will permit a new teacher to be certified and work in the field before he or she has taken a special education class as long as he or she completes a special education course before renewal of certification.) With the proliferation of alternate routes into the classroom, programs like Teach for America, leaders may need to ask faculty whether they have taken at least one course in special education. Rather than formal university coursework, a leader can encourage the use of other learning tools such as webinars, workshops, conferences, book groups, lesson study or other activities that provide fertile ground to start conversations about inclusive practices and how educators can better meet the needs of diverse learners.

\subsubsection{Experience with Children with Mild to Moderate Disabilities}

Leaders have a lot of discretion when it comes to how much time educators spend working with children identified with mild to moderate disabilities. Respondents with minimal experience with children with mild to moderate disabilities ( 1 hour or fewer a month) reported lower scores on the cognitive subscale and full scale $\left(\mathrm{F}_{\text {full }(3,726)}=5.04, \mathrm{p}=.002 \mathrm{n}^{2}=0.021\right)$.

The full scale results for educators that reported minimal experience ( 1 hour or fewer a month) were significantly lower than all the other groups $(\mathrm{p}=.016)$, but the other three groups were not statistically different. Those educators who identified that they have extensive experience reported lower scores than educators reporting considerable $(\mathrm{p}=.009)$, some $(\mathrm{p}=.028)$ and even lower (although not significantly) than educators who indicated that they have minimal experience $(\mathrm{p}=.059)$.

Based on these data, it appears that educators with the most experience with students with mild to moderate disabilities may need additional support to bolster their affective and behavioral domains of attitude. These quantitative data do not provide sufficient explanation as to why these educators hold these less positive attitudes but a school leader has the opportunity to ask and would be wise to listen to what these educators say and what they leave unsaid. When a leader gleans this information from their faculty, they should be encouraged to share it with other local leaders so that a community is created that will support the educators who have the greatest amount of contact with children with mild to moderate disabilities and therefore the greatest influence with these children.

Providing support for educators who have the most extensive contact with children with mild to moderate disabilities and improving their attitudes will likely have the greatest return on investment. It is troubling that the group with the largest amount of contact with children with mild to moderate disabilities has the lowest affective and behavioral scores. Perhaps revising school schedules, careful heterogeneous grouping or innovative co-teaching models will move more educators into the middle two 
categories of contact with students with mild to moderate disabilities, demonstrating more positive attitudes, and reduce the number of educators that fall on either end of the range.

\section{$7 \quad$ Significance and Conclusions}

Some teacher level factors that impact inclusion can be addressed at the school/district level. While educational leaders may not be able to control the makeup of their faculty, they can enhance the relevance and quality of the professional development they offer. Specifically, if a leader identifies that the current faculty has a group of new faculty members, then the leader can offer professional development that is tailored to the groups with an emphasis on the knowledge components that contribute to attitude. Additionally, the leader can increase transparency and build capacity through modeling by explicitly discussing how grouping and differentiation are used in planning professional development for the school with this group of new educators and establishing policies that espouse and protect these ideals. Not only does this modeling increase the knowledge base of the new educators, but also the policies serve as tangible evidence of norms and expectations for the school as a whole. These norms and expectations influence the individual educator's view of his or her professional role and responsibilities to meet the needs of every child in his or her care regardless of any special education needs.

Ultimately, the characteristics of schools and educators can be used to guide decisions regarding professional development to influence educator attitudes towards inclusion of children with mild to moderate disabilities. Through this influence, along with attention to the subjective norms of faculty and reaffirming that educators do, in fact, have the ability to impact student outcomes, behavioral intentions and observable behaviors can be positively changed. Districts, schools, and individual leaders can change pedagogical practice through assessing educator attitudes, providing differentiated professional development, and establishing policies that support inclusive education.

\section{References}

1. Ahmmed, M., Sharma, U., \& Deppeler, J. (2012). Variables affecting teachers' attitudes towards inclusive education in Bangladesh. Journal of Research in Special Educational Needs, 12(3), $132-140$. http://doi.org/10.1111/j.1471-3802.2011.01226.x

2. Ainscow, M., Dyson, A., \& Weiner, S. (2014). From exclusion to inclusion: A review of international literature on ways of responding to students with special education needs in schools. En Clave Pedagógica - Universidad de Huelva, 13, 13-30.

3. Ajzen, I. (1991). The Theory of Planned Behavior. Organisation Behavior and Human Decision Process, 50(2), 179-211. http://doi.org/10.1016/0749-5978(91)90020-T.

4. Avramidis, E., Bayliss, P., \& Burden, R. (2000a). A Survey into Mainstream Teachers' Attitudes Towards the Inclusion of Children with Special Educational Needs in the Ordinary School in one Local Education Authority. Educational Psychology, 20(2), 191-211. http://doi.org/10.1080/713663717.

5. Avramidis, E., Bayliss, P., \& Burden, R. (2000b). Student teachers' attitudes towards the inclusion of children with special educational needs in the ordinary school. Teaching and Teacher Education, 16(3), $277-293$. http://doi.org/10.1016/S0742-051X(99)00062-1.

6. Avramidis, E., \& Norwich, B. (2002). Teachers' attitudes towards integration / inclusion: a review of the literature. European Journal of Special Needs Education, 17(2), 129-147. http://doi.org/10.1080/08856250210129056

7. Ball, K., \& Green, R. L. (2014). An investigation of the attitudes of school leaders toward the inclusion of students with disabilities in the general education setting. National Forum of Applied Educational Research Journal, 27(1/2), 57-76.

8. Barnes, M., \& Gaines, T. (2015). Teachers' Attitudes and Perceptions of Inclusion in Relation to Grade Level and Years of Experience. ... for Inclusive Education. Retrieved from

http://corescholar.libraries.wright.edu/ejie/vol3/iss3/3/

9. Beacham, N., \& Rouse, M. (2012). Student teachers' attitudes and beliefs about inclusion and inclusive practice. Journal of Research in Special Educational Needs, 12(1), 3-11. 
10.Bock, G., Zmud, R., Kim, Y., \& Lee, J. (2005). Behavioral intention formation in knowledge sharing: Examining the roles of extrinsic motivators, social-psychological forces, and organizational climate. MIS Quarterly. Retrieved from http://www.jstor.org/stable/25148669

11.Boivie, I. (2011). The Three Rs of Teacher Pension Plans: Recruitment, Retention, and Retirement. Issue Brief. Washington: National institute on retirement security

12.Brunswik, E. (1955). Representative design and probabilistic theory in a functional psychology. Psychological Review, 62(3), 193-217. http://doi.org/10.1037/h0047470

13.Bryk, A., \& Schneider, B. (2002). Trust in Schools: A Core Resource for Improvement: A Core Resource for Improvement. Russell Sage Foundation. Retrieved from https://books.google.com/books?hl=en\&lr=\&id=fOSFAwAAQBAJ\&pgis=1

14.Council of Chief State School Officers [CCSSO]. (2011). InTASC model core teaching standards. Retrieved from http://www.ccsso.org/Resources/Resources_Listing.html?search=model+core+teaching+Standards

15.Cullen, J. P. \& Noto, L. A. (2007). The assessment of pre-service general education teachers' attitudes toward the inclusion of students with mild to moderate disabilities. Journal for the Advancement of Educational Research, (3)1, 23-33.

16.Cullen, J. P., Gregory, J. L, \& Noto, L. A. (2010). The Teacher Attitudes toward Inclusion Scale (TATIS). In Eastern Educational Research Association (pp. 1-20).

17.De Bono, E. (1985). Six Thinking Hats: An Essential Approach to Business Management from the Creator of Lateral Thinking. Boston: Little, Brown and Co.

18.deBettencourt, L. U. (1999). General Educators' Attitudes toward Students with Mild Disabilities and Their Use of Instructional Strategies: Implications for Training. Remedial And Special Education, 20(1), 27-35.

19.Dingle, M. P., Brownell, M. T., Leko, M. M., Boardman, A. G., \& Haager, D. (2011). Developing effective special education reading teachers: The influence of professional development, context, and individual qualities. Learning Disability Quarterly, 34(1), 87-103.

20.Dudley-Marling, C., \& Burns, M. (2013). Two perspectives on inclusion in the United States. Global Education Review, 1(1), 14-31. Retrieved from http://ger.mercy.edu/index.php/ger/article/view/10.

21.Education for All Handicapped Children Act (1975).

22.Elmore, R. (2000). Building a New Structure For School Leadership Building a New Structure. American Educator, 23. Retrieved from http://www.politicalscience.uncc.edu/godwink/PPOL8687/Wk10 March 22 Accountability/Elmore Building a New Structure for Leadership.pdf

23.Fishbein, M., \& Ajzen, I. (1972). Attitudes and Opinions. Annual Review of Psychology, 23(1), 487-544. http://doi.org/10.1146/annurev.ps.23.020172.002415

24.Ford, J. (2013). Educating Students with Learning Disabilities in Inclusive Classrooms. Electronic Journal for Inclusive Education. Retrieved from http://corescholar.libraries.wright.edu/ejie/vol3/iss1/2

25.Fuchs, W. (2010). Examining Teachers' Perceived Barriers Associated with Inclusion. Southeastern Regional Association of Teacher Educators Journal, 19, 30-36. Retrieved from http://eric.ed.gov/?id=EJ948685.

26.Furman, G., \& Shields, C. (2005). How can educational leaders promote and support social justice and democratic community in schools. In W. A. Firestone \& C. Riehl (Eds.), A new agenda for research in educational leadership (pp. 119-137). New York: Teachers College Press. Retrieved from

http://www.rothaleading.com/b_file/110330033536A New Agenda for Research in Educational Leadership.pdf\#page=132.

27.Gal, E., Schreur, N., \& Engel-Yeger, B. (2010). Inclusion of Children with Disabilities: Teachers' Attitudes and Requirements for Environmental Accommodations. International Journal Of Special Education, 25(2), 89-99.

28.Glazzard, J. (2011). Perceptions of the barriers to effective inclusion in one primary school: voices of teachers and teaching assistants. Support for Learning, 26(2), 56-63.

29.Gregory, J. L. (2013). Lecture is not a Dirty Word, How to Use Active Lecture to Increase Student Engagement. International Journal of Higher Education, 2(4). http://doi.org/10.5430/ijhe.v2n4p116

30.Gregory, J. L. (n.d.). Trust Relationships in Schools: Supporting or Subverting Implementation of School-Wide Initiatives. Manuscript in Preparation.

31.Gregory, J. L., \& Fitzpatrick-Hanna, D. (n.d.). Growing school climate through the CT SEED teacher evaluation model; relationships of trust and power. Manuscript in Preparation.

32.Gregory, J. L., Lewis, D., Noto, L., \& Margolis, E. (2011). Aligning Voices, Urban Teachers and Leaders. In NERA Conference Proceedings 2011 (pp. 1-25). Rocky Hill, CT: DigitalCommons@UConn. Retrieved from http://digitalcommons.uconn.edu/nera_2011/9/ 
33.Gregory, J. L. \& Noto, L. A. (2012). Attitudes towards teaching all students (ATTAS-mm) technical report. ERIC Document: ED537530.

34.Leithwood, K., \& Riehl, C. (2003). What we know about successful school leadership. Retrieved from http://www.leadersdesktop.sa.edu.au/leadership/files/links/school_leadership.pdf

35.Netemeyer, R., Ryn, M. Van, \& Ajzen, I. (1991). The theory of planned behavior. Orgnizational Behavior and Human Decision Processes, 50, 179-211. http://doi.org/10.1016/0749-5978(91)90020-T

36.No Child Left Behind Act. Reauthorization of the Elementary and Secondary Education Act. (2001).

37.Noto, L., \& Gregory, J. L. (2011). Is it possible to impact the attitudes of pre-service general education teachers about the inclusion of students with disabilities? In 2011 HICE Proceedings (pp. 1398-1412). Honolulu, HI.

38.Nuhfer, E. B. (2005). De Bono's Red Hat on Krathwohl's Head: Irrational Means to Rational Ends - More Fractal Thoughts on the Forbidden Affective: Educating in Fractal Patterns XIII. National Teaching and Learning Forum, (14)5, 7-11.

39.O'Rourke, J., Main, S., \& Cooper, M. (2008). Secondary v K-7: Pre-Service Teachers' Attitudes towards Inclusion. International Journal Of Learning, 15(7), 97-104.

40.Parasuram, K. (2006). Variables that affect teachers' attitudes towards disability and inclusive education in Mumbai, India. Disability and Society, 21(3), 231-242.

41.Peterson, K., \& Deal, T. (1998). How leaders influence the culture of schools. Educational Leadership. Retrieved from http://ascd.asia/ASCD/pdf/journals/ed_lead/el199809_peterson.pdf

42.Pritchard, K. (2014). A Comparative Study of Classroom Teachers' Perceptions Towards Inclusion. GardnerWebb University. Retrieved from http://gradworks.umi.com/36/42/3642222.html

43.Reeves, D. B. (2011). From Differentiated Instruction to Differentiated Assessment. ASCD Express, 6(20). Retrieved from http://www.ascd.org/ascd-express/vol6/620-reeves.aspx

44.Sheeran, P., Norman, P., \& Orbell, S. (1999). Evidence that intentions based on attitudes better predict behaviour than intentions based on subjective norms. European Journal of Social .... Retrieved from http://www.researchgate.net/profile/Paschal_Sheeran/publication/232509948_Evidence_that_intentions_based _on_attitudes_better_predict_behaviour_than_intentions_based_on_subjective_norms/links/00b4952698826 b6a59000000.pdf

45.Shippen, M. E., Flores, M. M., Crites, S. A., Patterson, D., Ramsey, M. L., Houchins, D. E., \& Jolivette, K. (2011). Classroom Structure and Teacher Efficacy in Serving Students with Disabilities: Differences in Elementary and Secondary Teachers. International Journal of Special Education, 26(3), 36-44.

46.Stuart, S., \& Rinaldi, C. (2009). A collaborative planning framework for teachers implementing tiered instruction. Teaching Exceptional Children, 42(2), 52-57. Retrieved from

http://search.proquest.com/openview/b7c0e348e6a7a49011525936449f75e5/1?pq-origsite=gscholar

47.The New Teacher Project (TNTP). (2012, March). Teacher experience: What does the research say? [Fact sheet]. Retrieved from http://tntp.org/assets/documents/ TNTP_FactSheet_TeacherExperience_2012.pdf

48.Tomlinson, C. (1999). Mapping a route toward differentiated instruction. Educational Leadership, 57(1), $12-16$. Retrieved from http://www.palmbeachschools.org/imlms/documents/MappingaRouteToward_DI.pdf

49.Watzlawick, P., Weakland, J., \& Fisch, R. (1974). Change: Principles of Problem Formation and Resolution. New York: W. W. Norton and Co.

50.Whitaker, T. (2003). What Great Principals Do Differently. Larchmont, NY: Eye on Education. Retrieved from http://shiftingthemonkey.com/WhatGreatPrincipalsDoDifferentlyLong.pdf

51.Wilde, A., \& Avramidis, E. (2011). Mixed feelings: towards a continuum of inclusive pedagogies. Education 3-13, 39(1), 83-101. http://doi.org/10.1080/03004270903207115. 